\title{
Narrative Development and Supported Employment of Persons with Severe Mental Illness
}

\author{
par \\ Kelly Ann Cartwright
}

Département de psychologie

Faculté des arts et des sciences

Essai présenté à la Faculté des arts et des sciences en vue de l'obtention du grade de Doctorat en psychologie option psychologie clinique

Août, 2014

(C) Kelly Ann Cartwright, 2014 



\section{Résumé}

Introduction. Le programme de réinsertion au travail de type soutien en emploi (SE) est reconnu comme étant le plus efficace des programmes de réintégration professionnelle pour des clients atteints de troubles mentaux graves, atteignant des taux d'emploi de 40 à $60 \%$. Pourtant, nous en connaissons peu sur le lien entre les indicateurs positifs d'emploi et les aspects subjectifs du rétablissement, tels que ceux retrouvés dans les récits narratifs.

Objectif. La présente étude investiguait la relation prospective entre le développement du discours narratif au début de la réadaptation professionnelle et les indicateurs d'emploi huit mois plus tard.

Méthode. À l'aide d'un échantillon de 38 personnes ayant des troubles mentaux graves (TMG) inscrites dans un programme de réinsertion au travail de type SE, l'étude longitudinale a examiné le lien entre la perception subjective du soi, à l'aide d'une mesure quantitative du développement des discours narratifs et des indicateurs d'emploi (p. ex. : employé ou sans emploi; nombre d'heures travaillées par semaine). Les auteurs ont exploré également l'évolution des récits narratifs au fil du temps.

Résultats. Les résultats ont démontré que 57,9\% des participants obtenaient un emploi. Le développement des discours narratifs ne corrélait pas à l'obtention d'un emploi. Les participants sans emploi fournissaient des récits narratifs plus développés que les travailleurs par rapport à leur perception de proximité émotionnelle à autrui et de leur sentiment de valeur sociale, ainsi que par rapport au développement global de leurs discours. En outre, plus de proximité émotionnelle initiale prédisait moins d'heures travaillées huit mois plus tard, tout en contrôlant pour le fonctionnement exécutif, les symptômes négatifs et l'estime de soi. Enfin, alors que ceux qui travaillaient ne démontraient aucune évolution dans leurs discours narratifs, ceux qui étaient 
sans emploi augmentaient dans le niveau d'agentivité durant les huit mois de participation dans le programme SE.

Conclusions. Les résultats démontrent que le rétablissement subjectif n'est pas nécessaire pour l'obtention d'un emploi compétitif. La relation entre les indicateurs de travail et le discours narratif mérite de plus amples recherches afin de l'étudier plus en profondeur.

Mots clés : troubles mentaux graves, psychose, récits narratifs, réinsertion au travail, rétablissement, psychologie clinique 


\begin{abstract}
Introduction. Supported Employment (SE) is widely recognized as the most effective vocational program in psychiatric rehabilitation, resulting in employment rates of 40 to $60 \%$. However, little is known about the link between positive work outcomes and subjective aspects of recovery, such as those found in narratives.
\end{abstract}

Objective. The present study investigated the prospective relationship between narrative development at the start of vocational rehabilitation and positive work outcomes.

Method. Using a sample of 38 people with Severe Mental Illness (SMI) participating in Supported Employment, the authors employed a time-limited, mixed-method longitudinal design to examine the relationship between baseline self-experience, as measured using a quantitative measure of narrative development, and employment outcomes (competitively employed or not employed; hours worked per week) eight months later. The authors also explored whether narratives evolved over the course of the study.

Results. The results showed that $57.9 \%$ of participants were competitively employed at the end of the study. Narrative development was unrelated to work outcome for those with competitive employment. Unemployed participants provided more developed narratives than workers with respect to emotional connectedness, social worth and overall development of narratives. In addition, higher emotional connectedness at the start of SE was predictive of fewer hours worked eight months later, controlling for executive functioning, negative symptoms and self-esteem. Finally, while workers showed no changes in narratives over time, those without work demonstrated increased agency over the eight months of participation in SE. 
Conclusions. The results demonstrated that narrative recovery is not related to the ability of persons with SMI to find work or to work more hours. The relationship between work outcomes and narratives warrants further study.

Keywords: Severe Mental Illness, psychosis, schizophrenia, Supported Employment, narratives, self-experience, recovery, clinical psychology 


\section{Table des matières}

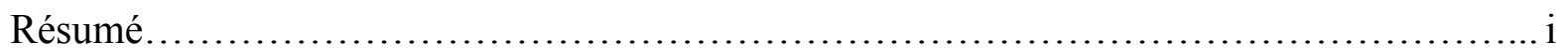

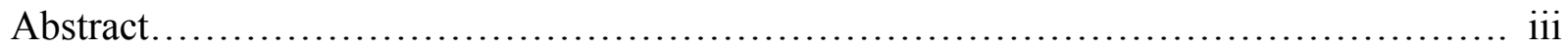

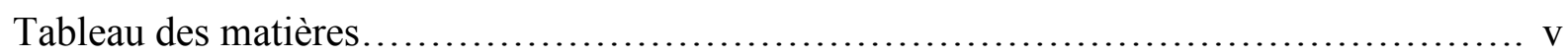

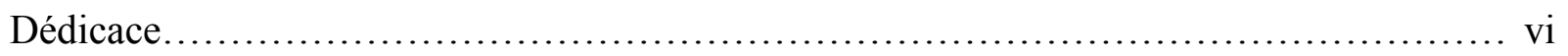

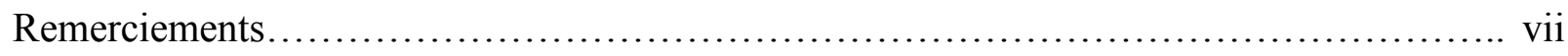

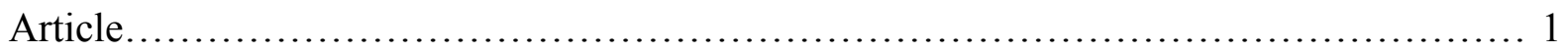

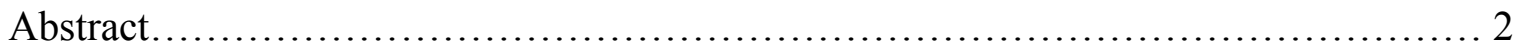

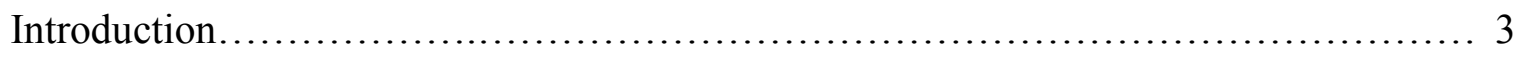

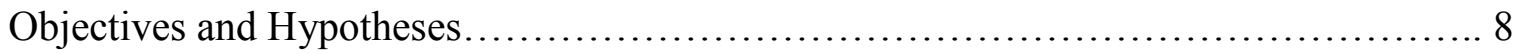

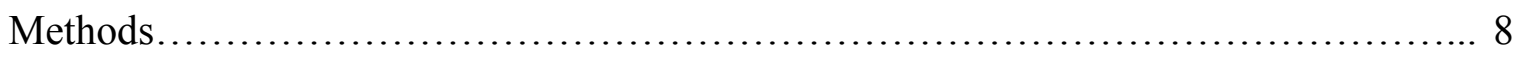

Design and Ethical Approval.............................................. 8

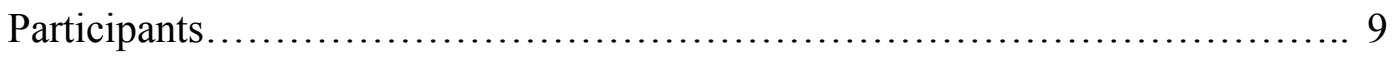

Measures........................................................................ 9

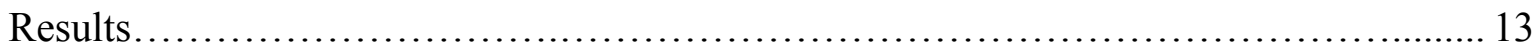

Discussion.......................................................................... 14

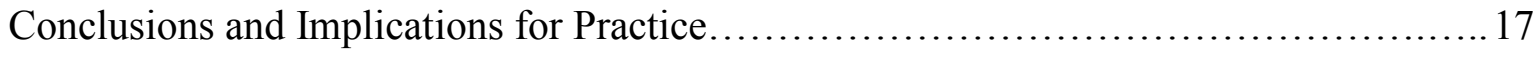

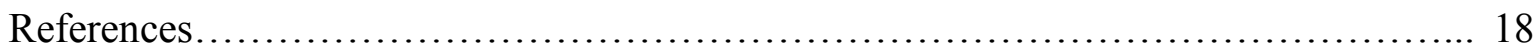

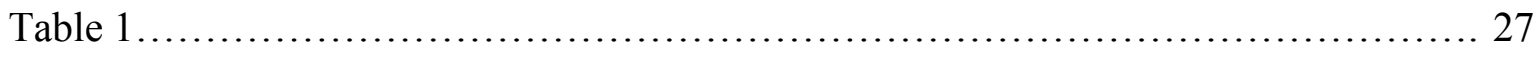

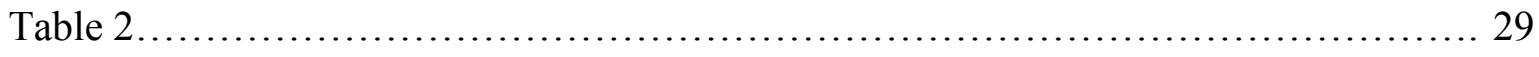

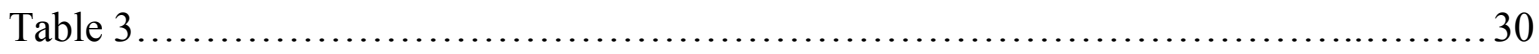

Annexe A : Consignes et texte pour l'entrevue Indiana Psychiatric Illness Interview......... viii Annexe B : Grille de cotation pour la mesure Scale to Assess Narrative Development....... x 
In loving memory of my mother,

Olive Miller,

who instilled in me from an early age

the value of obtaining an education 


\section{Remerciements}

Merci à ma directrice d'essai, Tania Lecomte, pour ton support continu, ta douce patience, ton ouverture d'esprit, tes conseils précieux et, surtout, ta grande expertise. Merci de m'avoir accueilli dans ton laboratoire; tu as influencé ma vie.

Thank you to my children, Tristan and Émile, my two rays of sunshine and the coolest kids anywhere. You inspire and challenge me each day. I hope that one day you too will follow your dreams through to the end. Never underestimate what you are capable of! And, above all, never lose those beautiful smiles.

Merci à mes chères amies, Nancy et Nat, qui m'ont encouragé tout au long. Merci pour les rires, l'écoute, les distractions et l'aide pratique... Merci pour qui vous êtes.

À toutes les filles de la cohorte : nous avons partagé un parcours extraordinaire ensembles. Vous êtes d'exceptionnelles jeunes femmes. J'ai hâte de suivre vos carrières.

Effie : Thanks for your help in the eleventh hour. What would I have done without you?

Merci à mes collègues du labo, avec une mention particulièrement chaleureuse pour Marjo et Guillaume pour leur aide avec la cotation, pour Mélanie pour sa vitesse et sa patience sans limites, pour Rowena (« classmate, labmate, stagemate »), et pour Karine (a.k.a. Life Saver) pour son assistance indispensable avec la révision de ce document.

Thanks to Betty. My clean house was a bigger comfort than you ever can imagine. J'aimerais exprimer mon appréciation sincère à Louis Durocher pour son soutien financier pendant mes études doctorales.

Finalement, nous reconnaissons avec gratitude la subvention de la plus grande étude par le Canadian Institutes for Health Research-Instituts de la recherche en santé du Canada (numéro de subvention 123305) 
Running Head: NARRATIVE DEVELOPMENT AND SUPPORTED EMPLOYMENT

Narrative Development and Supported Employment of Persons with Severe Mental Illness

Authors: Kelly Cartwright, D.Psy Cand; Tania Lecomte, Ph.D

Keywords: Severe Mental Illness, psychosis, schizophrenia, Supported Employment, narratives, self-experience, recovery

Manuscrit en préparation pour soumission au Psychiatric Rehabilitation Journal 


\begin{abstract}
Objective: The present study investigated the prospective relationship between narrative development at the start of vocational rehabilitation and positive work outcomes in a Supported Employment (SE) context. Methods: Using a sample of 38 people with Severe Mental Illness (SMI) participating in SE vocational programming, the authors employed a time-limited, mixedmethod longitudinal design to examine the relationship between baseline self-experience, as measured using a quantitative measure of narrative development, and employment outcomes (competitively employed or not employed; hours worked per week) eight months later. The authors also explored whether narratives evolved over the course of the study. Results: The results showed that $57.9 \%$ of participants were competitively employed at the end of the study. Narrative development was unrelated to work outcome for those with competitive employment. Unemployed participants had higher initial STAND ratings than workers with respect to emotional connectedness, social worth and overall development of narratives. In addition, higher emotional connectedness at the start of SE was predictive of fewer hours worked eight months later, controlling for executive functioning, negative symptoms and self-esteem. Finally, while workers showed no changes in narratives over time, those without work demonstrated increased agency over the eight months of the study. Conclusion \& Implications for Practice: The results demonstrated that narrative recovery is not related to the ability of persons with SMI to find work or to work more hours. The relationship between work outcomes and narratives merits further study.
\end{abstract}




\section{Introduction}

Persons with Severe Mental Illness (SMI) are disproportionately unemployed (Bond \& Drake, 2008) as well as overrepresented among disability benefits recipients (Drake \& Bond, 2008), and chronic unemployment for persons with SMI has been associated with both poor mental health (Wewiorski \& Fabian, 2004) and poverty (Cook, 2006). Conversely, the relationship between employment and recovery is strong, positive and multifaceted. Most persons with SMI express an interest in work (Mueser, Salyers, \& Mueser, 2001), and employment has been associated with important clinical and nonclinical benefits for this population, including symptoms reduction, increased social contacts and better global functioning (Burns et al., 2008). Research has also found the benefits of work to be greater when employment was paid as compared to unpaid (Bell \& Lysaker, 1997; Bryson, Lysaker, \& Bell, 2002) and when a position was competitive (defined as a regular job open to anyone in the labour market and paid at the same rate) versus one in a protected or noncompetitive setting (Bond et al., 2001).

One factor that has been shown to vastly improve employment outcomes for this population is participation in a vocational program adhering to the Individual Placement and Support (IPS) model of Supported Employment (SE; Dixon et al, 2010). This model, which follows six core principles and sets competitive employment as its goal (Bond, 1998), has consistently been found across a large number of studies to improve positive work outcomes as compared to other vocational interventions by a ratio of more than 2:1 (Drake \& Bond, 2014), yielding an employment rate of between approximately 40 to 60 percent (Bond, Drake, \& Becker, 2008; Latimer et al., 2006). Research has demonstrated that such outcomes do not appear to be impacted by background demographic, clinical or employment characteristics 
(Campbell, Bond \& Drake, 2011). However, a paucity of studies has addressed the link between SE outcomes and subjective factors, such as those expressed in individuals' accounts of their life stories, called personal narratives.

\section{Narrative Changes in SMI}

Schizophrenia and other SMIs, while consisting of a variety of symptoms and deficits, have elsewhere been considered as having a profoundly detrimental impact on the sense of subjective self of the person as expressed in their narratives (Lysaker \& Lysaker, 2008; Sass \& Parnas, 2001; Zahavi, 2002). Disruptions of self-narratives are often particularly profound and pronounced during psychosis (Holma \& Aaltonen, 1997; Lysaker, Wickett, Wilke, \& Lysaker, 2003) as well as during major depression. Schizophrenia has been conceptualized as a selfdisorder in which one finds distortions of the act of awareness impacting the experience of a first-person perspective in the world (Akroyd, 2013), altering the experience of the self as the constituting agent of thought, emotion and action (Zahavi, 2002) and resulting in self-stories that are missing a protagonist (Lysaker, Wickett, Wilke, et al., 2003). These stories have been found to show deficits not only in volition, but also in the perception of one's social worth, in one's emotional connectedness and in the ability to make sense of mental illness as a part of life (Lysaker, Lintner, Luedtke, \& Buck, 2009). Similarly, although research into changes in selfexperience associated with depression is more scant, a loss of self-identity, of social connectedness and of control over life decisions were common narrative themes in two studies (Borba et al., 2011; Cornford, Hill, \& Reilly, 2007) as well as two first-person accounts (Kean, 2009; Rhodes \& Smith, 2010).

\section{Subjective Recovery, Narratives and the Return to Work}

Paralleling the identification of subjective aspects of SMI, there has been a shift in the 
conceptualization of recovery from mental illness to include subjective or personal aspects of recovery (such as self-experience and appraisal of life circumstances) as both distinct from and related to objective (clinical) aspects (Lysaker \& Buck, 2008). Current thought suggests that a central task in subjective recovery is the reconstruction of a sense of self, including the recovery of agency (defined as viewing oneself as an active agent in one's life rather than a victim of circumstances) and the perception of mental illness as but one component of a more complex and multifaceted identity (Davidson \& Strauss, 1992; Polkinghorne, 1996; Yanos, Roe, \& Lysaker, 2010). Narrative reconstruction is thus thought to be central to recovery.

With respect to the relationship between narratives and vocational recovery, studies are scant (Yanos, Roe, et al., 2010). There is some limited empirical evidence that self-stories characterized by a diminished self-perception in the forms of illness identity (over-identification with mental illness and the role of the patient) and self-stigma (the process by which persons apply negative social judgments associated with an individual characteristic, such as mental illness, to themselves) represent an important barrier to employment (Corrigan, Powell, \& Rusch, 2012; Yanos, Lysaker, \& Roe, 2010). Vocational impairment in SMI has also been associated with lower levels of important aspects of self-experience, including a decreased understanding of mental illness (Erickson, Jaafari, \& Lysaker, 2011), impaired motivation (Davis, Nees, Hunter, \& Lysaker, 2004), and decreased job-related self-efficacy (Corbière, Mercier, Lesage, \& Villeneuve, 2005). Empirical studies thus appear to support a link between self-experience and employment outcomes, although none to date have used narrative measures.

Several qualitative studies have also investigated the relationship between self-experience and work. Cunningham and associates (2000) compared the narratives of 17 persons with SMI participating in Assertive Community Treatment programs. Those who found work described a 
more complex self, portraying mental illness as only one facet of identity, in contrast to unemployed participants or those unable to maintain employment, who tended to deny or overidentify with mental illness. Employed participants also referred to more proactive coping strategies. In another study, Provencher and associates (Provencher, Gregg, Mead, \& Mueser, 2002) analyzed the interview transcriptions of 14 persons with psychiatric disabilities (12 with SMI and two with post-traumatic stress disorder), identifying three discrete recovery profiles. For these individuals, work and recovery were intimately linked. Both Profile 1 and 2 groups contained both working and not working individuals as well as some not looking for work. The Profile 1 group perceived uncertain recovery and vocational futures, referred to superficial social connections and described passive or avoidant coping strategies and a high degree of illness identity. The Profile 2 group, which saw recovery as self-reconstruction, portrayed themselves as building a more active sense of self focused on illness management and a return to social and work function. In contrast, the Profile 3 group, which was comprised of working individuals only, saw recovery as an opportunity to challenge themselves and work as a means to selfactualization. Furthermore, similar to the employed participants in Cunningham and associates' (2000) study, they defined themselves in terms of their multiple roles rather than their illness. They also indicated a high degree of self-empowerment and self-efficacy, as well as reciprocal social relationships. Taken together, these findings suggest working and work-related conceptualizations may be closely linked to the degree of narrative development with respect to understanding of illness, emotional connectedness to others and agency.

Moreover, with respect to the link between self-experience and work, some authors have suggested that a certain level of a priori narrative reconstruction and positive sense of self might be necessary in order to obtain and maintain work (Bebout \& Harris, 1995; Lysaker \& France, 
1999). In one qualitative study of 113 clients with SMI enrolled in vocational programs (Harris et al., 1997), the stories clients told themselves prior to vocational rehabilitation were related to work outcomes. For example, some, for whom work was an ill-defined notion, lacked the motivation required for a job search. Others with high illness identity did not see themselves as able to work and viewed work as a threat to their identity. Still other clients, viewing work as a "magic pill", demonstrated improved job-seeking motivation coupled with impaired job retention. In another study, Lysaker and France (1999), analyzed case studies of six clients with SMI who were participating in vocational rehabilitation, finding that the narratives of five out of the six evolved longitudinally from a description of why work was impossible to include the possibility of work. The authors suggested that this latter conception appeared to be a prerequisite to eventual employment. Along the same lines, Strickler (2014), in his first-person retrospective account, describes the perception of work as a viable possibility as preceding his active and successful pursuit of employment. Collectively, these three studies provide a framework in which participation in or withdrawal from work can be understood as possibly being related to the degree of narrative reconstruction before beginning vocational rehabilitation. Unfortunately, this body of research has a number of limitations. Many of the cited qualitative studies had a small sample size, and only one was prospective in nature, thus precluding the establishment of temporal precedence of improved narratives relative to work. Further, there is no prospective empirical research on work outcomes with narrative development as its focus. Investigation of the relationship between self-experience, as expressed in narratives, and employment thus seems paramount. 


\section{Objectives and Hypotheses}

The present study addresses this lack of research by investigating the possible predictive relationship between subjective self-experience in SMI, as measured via narratives, and work outcomes in a Supported Employment context. Specifically, we asked whether a certain level of narrative development is a necessary predisposing factor to working and, if so, what aspects of narrative are most important in this process. We hypothesized that: (1) competitively employed participants at eight-months follow-up would provide more developed personal narratives at baseline than unemployed participants; and (2) more developed narratives at baseline would predict increased work intensity (defined as the number of hours worked per week) at follow-up, controlling for factors shown to correlate with narrative ratings, namely negative symptoms, executive functioning and self-esteem (Lysaker, France, Hunter, \& Davis, 2005; Lysaker, Ringer, Maxwell, McGuire, \& Lecomte, 2010; Lysaker, Taylor, et al., 2006; Lysaker, Wickett, \& Davis, 2005). In addition, as an exploratory question, we examined changes in narratives over time as a function of competitive employment status.

\section{Methods}

\section{Design and Ethical Approval}

The data originated from a mixed-methods, time-limited longitudinal design involving a total of 100 participants recruited from SE services in the metropolitan region of Montreal, half of whom received an eight-session cognitive-behaviour intervention (Lecomte, Corbière, \& Lysaker, 2014). A battery of measures was administered by trained undergraduate and graduate students at baseline (T0), two (T1), eight (T2) and 14 (T3) months later. Only data from baseline and $\mathrm{T} 2$ are presented here. The larger and the present studies were approved by the research ethics board at the University of Montreal. 


\section{Participants}

The present study employed a sample size of 40 participants registered in a Supported Employment program, randomly selected from the larger study. Participants provided informed, written consent to participate. Inclusion criteria included having a diagnosis of schizophrenia, schizoaffective, bipolar or major depressive disorders, beginning a search for employment or working fewer than 28 hours per week, being able to communicate in French or English and not having a known organic disorder or intellectual disability. Data from two participants not meeting these criteria were excluded from the study. The characteristics of the remaining 38 participants are presented in Table 1.

\section{Measures}

Sociodemographic Information. Data gathered at baseline using the Canadian Version of the PSR Toolkit (Arns, 1998) were used to describe the sample.

Narratives. Narratives were gathered using the Indiana Psychiatric Illness Interview (IPII; Lysaker, Clements, Plascak-Hallberg, Knipscheer, \& Wright, 2002), a semi-structured interview prompting participants to tell a narrative about their lives, their perception of their mental illness and its impact on their lives and their future expectations, including for work. It consists of five global questions plus additional sub-questions adjusted for verbal fluidity. IPII transcriptions taken at baseline and $\mathrm{T} 2$ were scored by two trained independent raters using the Scale to Assess Narrative Development (STAND; Lysaker et al., 2003).

Self-Experience. The STAND (Lysaker et al., 2003) consists of four subscales reflecting variations in subjects' perceptions of their mental illness (Illness Conception, IC), their emotional connectedness to others (Lack of Alienation, AL), their ability to influence their own lives (Agency, AG) and their sense of making a valuable contribution to others or to society 
(Social Worth, SW). These subscales assess aspects of self-experience associated with SMI by operationalizing the development of self-narratives obtained using the IPII along on a 5-point scale, where 1 indicates the absence of the self-concept in the narrative and 5 indicates its full development. The Total score, ranging between 4 and 20, provides an indicator of the degree of overall positive sense of self articulated in a narrative. The STAND has been shown to possess good interrater reliability for all subscales and the Total score, good internal consistency and satisfactory construct validity (Lysaker, Buck, Hammoud, Taylor, \& Roe, 2006; Lysaker, France, et al., 2005; Lysaker et al., 2010; Lysaker, Taylor, et al., 2006; Lysaker, Wickett, et al., 2005). STAND subscale scores for $25 \%$ of transcripts were co-verified to ensure an interrater difference of no more than 0.5 on any subscale, with differences of more than 0.5 being resolved through discussion. Satisfactory interrater coefficients were found.

Work Outcome. Participants's self-reports of Competitive Employment Status (employed or unemployed) and Work Intensity (number of hours worked per week) were gathered at T2.

Control variables. The study controlled for the following three variables found to correlate with STAND scores, using measures taken at baseline:

(a) Self-esteem. The Rosenberg Self-Esteem as a Worker Scale (RSEWS; Corbière, Lanctôt, Sanquirgo, \& Lecomte, 2009) was adapted from the Rosenberg Self-Esteem Scale (RSES; Rosenberg, 1965) by adding the words as a worker to the directive. As with the original RSES, items were answered using a Likert scale ranging from 1 (strongly disagree) to 4 (strongly agree), with five items being scored positively and five negatively according to established procedures. The internal consistency of the RSEWS has been shown to be satisfactory, with alpha coefficients of 0.85 and 0.75 respectively for individual ( 7 items) and social ( 3 items) selfesteem subscales. The convergent validity of the RSEWS is supported by the results of a study 
with 47 persons with severe mental disorders that found significant correlations between the RSEWS and two related measures previously validated for use with this population, namely the Self-Esteem Rating Scale-Short Form (SERS-SF; Lecomte, Corbière, \& Laisne, 2006) and the Career Self-Efficacy Scale-Short Form (CSES-SF; Corbière, Mercier, \& Lesage, 2004), with Pearson's $r$ correlations for all subscales of all measures ranging from 0.40 to $-0.67, p<.01$. Finally, the RSEWS was shown to be sensitive enough to capture variations in psychiatric diagnosis, with those with schizophrenia spectrum disorders demonstrating higher self-esteem than those with mood, anxiety or other psychotic disorders (Corbière, Lanctôt, Sanquirgo, \& Lecomte, 2009). The current study used the RSEWS total score only.

(b) Executive functioning. The Wisconsin Card Sorting Test (WSCT; Heaton, Chelune, Tally, Kay, \& Curtis, 1993), a measure of executive functioning, has been widely used to assess cognitive impairment in schizophrenia and other psychotic disorders. The WCST is a complex task in which cognitive impairments may disrupt problem solving and the flexibility of abstract thought processes required to complete the test. Performance on the Perseverative Errors (PE) subscale (defined as the number of incorrect responses using the same response pattern) has been repeatedly shown to be impaired in SMI and, moreover, to correlate with symptoms. For example, a meta-analysis including 16 studies of the WCST in schizophrenia spectrum disorders (combined $n=749$ ) found a significant correlation between perseverative errors and both negative symptoms $\left(r=0.27, p<.01, \chi^{2}=18.9\right)$ and disorganization $\left(r=0.25, p<.01, \chi^{2}=6.0\right)$ (Nieuwenstein, Aleman, \& de Haan, 2001). This finding replicates those of previous studies not included in the meta-analysis, such as that of Bell, Greig, Kaplan, and Bryson (1997), which found that perseveration correlated with not only well as negative symptoms and cognitive disorganization, but also sample characteristics such as age at intake, education, age at first 
treatment and duration of illness in a sample of 47 clinically stable outpatients with schizophrenia or schizoaffective disorder. The present study employed the Perseverative Errors (PE) and Categories Completed (CC; a measure of achievement) subscales of the computerized version of the WCST to assess executive functioning.

(c) Negative symptoms. The Brief Psychiatric Rating Scale-Expanded Version (BPRS-E; Ventura, Green, Shaner, \& Liberman, 1993) is a 24-item semi-structured interview that assesses on a seven-point scale the severity of various psychiatric symptoms contributing to respondents' functional impairment. Principal component analysis of the BPRS-E scores of 71 young adults diagnosed with schizophrenia yielded four components accounting for a total of $55.9 \%$ of the variance, namely Disorganization, Negative Symptoms, Positive Symptoms, and Depression. Evidence for the convergent validity of the BPRS subscales was provided by the significant respective correlations between participants' scores on the latter three components of the BPRSE with the Negative Symptoms $(r=.81, p<.001)$, Positive Symptoms $(r=.56, p<.001)$ and Anxiety/Depression $(r=.36, p<.01)$ subscales of Krawiecka, Goldberg, \& Vaughn's (1977) Psychiatric Assessment Scale (PAS; Dingemans, Linszen, Lenior, \& Smeets, 1995). Moreover, these results were very similar to those found by Ventura and associates using a similarly aged sample with schizophrenia (Ventura, Nuechterlein, Subotnik, \& Gilbert, 1995). Furthermore, a component analysis of the BPRS-E with an adolescent sample revealed a five factor model for use with that population which also included a Negative Symptoms subscale as distinct from Positive Symptoms, Depression, Mania and Disorganization (Van der Does, Linszen, Dingemans, Nugter, \& Scholte, 1993). While the factors in these studies were not reliably linked to illness subgroups, authors considered the BPRS-E as appropriate for tracking changes in severity of symptoms over time (Van der Does et al., 1993), as well as superior to the PAS for 
measuring symptom severity for research purposes (Dingemans et al., 1995). The present study employed the Negative Symptoms subscale to measure the severity of negative symptoms at intake. The doctoral-level interviewers were trained to reach interrater reliability according to UCLA gold standards (Ventura et al., 1993).

\section{Results}

Overall, $57.9 \%$ of participants $(n=22)$ were competitively employed at follow-up and 42.1\% $(n=16)$ were unemployed. Independent samples t-tests were conducted to ascertain whether baseline STAND subscale and Total scores were associated with employment status at eight-months follow up. As indicated in Table 2, the narratives of unemployed participants were rated higher on Lack of Alienation $(M=4.53 ; S D=0.79)$ than those of employed $(M=3.34, S D$ $=1.42$ ) participants, $t(36)=-3.40, p=.002$. Similarly, the Social Worth scores were higher for those without $(M=3.52, S D=0.69)$ than for those with $(M=2.74, S D=1.05)$ work, $t(36)=$ $2.58, p=.014$, as were STAND Total scores for unemployed $(M=16.71, S D=1.99)$ as compared to employed $(M=14.01, S D=4.02)$ participants, $t(32)=-2.73, p=.01$. The effect size for the difference in Lack of Alienation $\left(\eta^{2}=.24\right)$ was large (using effect size guidelines for $\eta^{2}$ as described by Tabachnick \& Fidell, 2013, pp. 55), while those for the differences in Social Worth and the Total score were medium $\left(\eta^{2}=.16\right.$ and .14 , respectively). Of these, only the comparisons using Lack of Alienation and the Total score reached statistical significance using a Bonferroni adjusted alpha level of .01 for multiple comparisons. The groups did not differ on Illness Conception or Agency.

As can be seen in Table 3, all STAND scores were positively intercorrelated and significant at $p<.01$ and $p<.001$. The Total score also correlated with self-esteem $(r=.29, p=$ $.045)$ and with the number of categories completed on the WCST $(r=.29, p=.001)$, as well as 
negatively with BPRS Negative Symptoms $(r=-.44, p=.004)$. Participants worked an average of $15.44(S D=15.25)$ hours per week. Work intensity correlated with negative symptoms $(r=$ $.35, p=.018$ ) and four out of five STAND scales (IC: $r=-.36, p=.017$; AL: $r=-.60, p<.001$; SW: $r=-.51, p=.001$; Total: $r=-.53, p=.001)$. Next, a stepwise multiple regression was conducted to evaluate whether baseline STAND scores were predictive of work intensity, controlling for baseline negative symptoms, executive functioning and self-esteem. The regression analysis revealed that Lack of Alienation scores significantly predicted work intensity, $F(1,33)=18.15, p<.001$, accounting for $35.5 \%$ of the variance. Moreover, as initial Lack of Alienation increased, the number of hours worked at follow-up decreased $(\beta=-0.584, p<.001)$. WCST, BPRS, RSEWS and remaining STAND scores were not significant predictors of work intensity.

Finally, a paired samples t-test was conducted to explore changes in narrative development over the course of the study as a function of competitive employment. For unemployed participants, there was a statistically significant increase in Agency from baseline $(M=4.23 ; S D=0.82)$ to follow-up $(M=4.72 ; S D=0.55), t(15)=-2.73, p=.012$ (two tailed). This represented a large effect size $\left(\eta^{2}=.33\right)$. No significant changes were observed for any other comparisons.

\section{Discussion}

Overall, the results did not support the hypotheses that employed participants would have more developed baseline narratives than unemployed participants and that more developed baseline narratives would predict greater work intensity at follow-up. While previous qualitative studies have suggested such an association, no such relationship was found with our sample using a quantitative measure. One explanation for this discrepancy could pertain to differences in 
the samples. The present study recruited participants in SE programs, whereas previous studies recruited individuals from Assertive Community Treatment and traditional vocational rehabilitation programs. Nevertheless, these results provide support for the notion that Supported Employment helps users find work regardless of lower initial narrative development.

The finding that subjects with decreased workplace participation, both in terms of employment status and hours worked, scored higher on baseline STAND measures was quite unanticipated, as well as counterintuitive. It could suggest that those with higher narrative development might be more difficult to place, having higher expectations and perhaps more demands regarding their preferred job.

The association between higher unemployment and higher emotional connectedness revealed in the present study goes in the same direction as results obtained by other authors. In their study examining the relationship between workplace participation and a measure of subjective recovery (the Recovery Assessment Scale; Giffort, Schmook, Woody, Vollendorf, Gervain, 1995) among 344 persons with psychiatric illness, Connell, King and Crowe (2011) found that nonworkers obtained significantly higher scores than workers on the Reliance on Others scale, as well as a trend approaching significance for Willingness to Ask for Help - two measures that may be considered as conceptually close to the Lack of Alienation subscale of the STAND. These differences may, as was suggested by Connell and associates (2011), indicate possible personal variation in independence or self-determination that may impact work outcomes. Moreover, the direction of this relationship may reveal different recovery profiles, such that those with more social connectedness may prioritize recovery in nonvocational domains, while those with fewer intimate ties may be more motivated to make work the primary focus. 
Also counterintuitive was the finding that participants not finding work showed an increase in agency over time. This result could be related to the realization, perhaps through their failed attempts at finding work, that they are responsible for what happens in their lives. It is also possible that individuals with a stronger sense of self are able to strengthen their sense of empowerment despite the ups and downs of work, or as a result of an extended job search. For example, they may have learned new skills through participation in Supported Employment that increased their sense of personal control. The lack of evolution in other STAND scores over time suggests that perhaps Supported Employment on its own does not, on the whole, promote narrative development. It is also possible that improvements in self-experience take place over a longer period of time than that of the present study.

Finally, we note the satisfactory internal consistency of the STAND, indicated by the moderate significant intercorrelations between subscales, as well as the significant correlation of STAND measures with self-esteem, negative symptoms and executive functioning. These results replicate those found in previous studies, demonstrating support for the use of the STAND with Supported Employment participants.

One limitation is the relatively brief time period (eight months) employed in the longitudinal analysis. It is possible that different results would be obtained over a longer time frame, by allowing for a longer delay to find work. In addition, the present study did not take into account clients' career goals, nor did it consider the type of job obtained. Furthermore, this study focused on differences relating to competitive workplace participation and did not assess the identification of activities in other socially important domains that may be related to alternate recovery paths. 
In order to better understand the relationship between narrative and work, future research could explore the importance of career goals and type of job sought in mediating the relationship between self-experience and work outcomes. Longitudinal studies employing a longer time frame would permit the evaluation of employment outcomes for participants with higher STAND scores, by allowing for a longer delay to find work. Moreover, the relationship between emotional connectedness, workplace participation and other domains of activity warrants further investigation.

\section{Conclusions and Implications for Practice}

In conclusion, although more research is warranted, it appears that better narrative development, or higher subjective recovery, is not necessary to obtain competitive work and to work many hours per week. Future studies should, however, investigate the relationship between narrative development, goal striving and other employment outcomes such as job maintenance and job satisfaction. 


\section{References}

Akroyd, M. J. (2013). You can't spell schizophrenia without an 'I': How does the Early Intervention in Psychosis approach relate to the concept of schizophrenia as an ipseity disturbance? Early Intervention in Psychiatry, 7(3), 238-246.

Arns, P. (1998). Canadian Version of the PSR Toolkit. Ontario Federation of Community Mental Health and Addiction Programs.

Bebout, R. R., \& Harris, M. (1995). Personal myths about work and mental illness: Response to Lysaker and Bell. Psychiatry, 58(4), 401-404.

Bell, M. D., Greig, T. C., Kaplan, E., \& Bryson, G. (1997). Wisconsin Card Sorting Test dimensions in schizophrenia: factorial, predictive, and divergent validity. Journal of Clinical \& Experimental Neuropsychology: Official Journal of the International Neuropsychological Society, 19(6), 933-941.

Bell, M. D., \& Lysaker, P. H. (1997). Clinical benefits of paid work activity in schizophrenia: 1year followup. Schizophrenia Bulletin, 23(2), 317-328.

Bond, G. R. (1998). Principles of the individual placement and support model: Empirical support. Psychiatric Rehabilitation Journal, 22(1), 11-23.

Bond, G. R., \& Drake, R. E. (2008). Predictors of competitive employment among patients with schizophrenia. Current Opinion in Psychiatry, 21(4), 362-369. doi: 10.1097/YCO.0b013e328300eb0e

Bond, G. R., Drake, R. E., \& Becker, D. R. (2008). An update on randomized controlled trials of evidence-based supported employment. Psychiatric Rehabilitation Journal, 31(4), 280290. doi: $10.2975 / 31.4 .2008 .280 .290$ 
Bond, G. R., Resnick, S. G., Drake, R. E., Xie, H., McHugo, G. J., \& Bebout, R. R. (2001). Does competitive employment improve nonvocational outcomes for people with severe mental illness? Journal of Consulting \& Clinical Psychology, 69(3), 489-501.

Borba, C. P. C., DePadilla, L., Druss, B. G., McCarty, F. A., von Esenwein, S. A., \& Sterk, C. E. (2011). A day in the life of women with a serious mental illness: A qualitative investigation. Women's Health Issues, 21(4), 286-292. doi: 10.1016/j.whi.2010.11.003

Bryson, G., Lysaker, P., \& Bell, M. (2002). Quality of life benefits of paid work activity in schizophrenia. Schizophrenia Bulletin, 28(2), 249-257.

Burns, T., Catty, J., White, S., Becker, T., Koletsi, M., Fioritti, A., et al. (2008). The impact of supported employment and working on clinical and social functioning: Results of an international study of individual placement and support. Schizophrenia Bulletin, 35(5), 949-958.

Campbell, K., Bond, G. R., \& Drake, R. E. (2011). Who benefits from supported employment: A meta-analytic study. Schizophrenia Bulletin, 37(Suppl 2), 370-380.

Connell, M., King, R., \& Crowe, T. (2011). Can employment positively affect the recovery of people with psychiatric disabilities? Psychiatric Rehabilitation Journal, 35(1), 59-63.

Cook, J. A. (2006). Employment barriers for persons with psychiatric disabilities: Update of a report for the President's Commission. Psychiatric Services, 57(10), 1391-1405.

Corbière, M., Lanctôt, N., Sanquirgo, N., \& Lecomte, T. (2009). Evaluation of self-esteem as a worker for people with severe mental disorders. Journal of Vocational Rehabilitation, $30(2), 87-98$. 
Corbière, M., Mercier, C., \& Lesage, A. (2004). Perceptions of barriers to employment, coping efficacy, and career search efficacy in people with mental health problems. Journal of Career Assessment, 12, 460-478.

Corbière, M., Mercier, C., Lesage, A., \& Villeneuve, K. (2005). L'insertion au travail des personnes souffrant d'une maladie mentale : analyse des caractéristiques de la personne. Canadian Journal of Psychiatry, 50(11), 722-733.

Cornford, C. S., Hill, A., \& Reilly, J. (2007). How patients with depressive symptoms view their condition: A qualitative study. Family Practice, 24(4), 358-364. doi:

10.1093/fampra/cmm032

Corrigan, P. W., Powell, K. J., \& Rusch, N. (2012). How does stigma affect work in people with serious mental illnesses? Psychiatric Rehabilitation Journal, 35(5), 381-384. doi: $10.1037 / \mathrm{h} 0094497$

Cunningham, K., Wolbert, R., \& Brockmeier, M. B. (2000). Moving beyond the illness: Factors contributing to gaining and maintaining employment. American Journal of Community Psychology, 28(4), 481-494. doi: 10.1023/A:1005136531079

Davidson, L., \& Strauss, J. S. (1992). Sense of self in recovery from severe mental illness. British Journal of Medical Psychology, 65(2), 131-145. doi: 10.1111/j.20448341.1992.tb01693.x

Davis, L. W., Nees, M. A., Hunter, N. L., \& Lysaker, P. H. (2004). Hopelessness as a predictor of work functioning among patients with schizophrenia. Psychiatric Services, 55(4), 434436. doi: 10.1176/appi.ps.55.4.434 
Dingemans, P. M., Linszen, D. H., Lenior, M. E., \& Smeets, R. M. (1995). Component structure of the expanded Brief Psychiatric Rating Scale (BPRS-E). Psychopharmacology, 122(3), 263-267.

Dixon, L. B., Dickerson, F., Bellack, A. S., Bennett, M., Dickinson, D., Goldberg, R. W., et al. (2010). The 2009 Schizophrenia PORT psychosocial treatment recommendations and summary statements. Schizophrenia Bulletin, 36(1), 48-70. doi: 10.1093/schbul/sbp115

Drake, R. E., \& Bond, G. R. (2008). The future of supported employment for people with severe mental illness. Psychiatric Rehabilitation Journal, 31(4), 367-376. doi:

10.2975/31.4.2008.367.376

Drake, R. E., \& Bond, G. R. (2014). Introduction to the special issue on individual placement and support. Psychiatric Rehabilitation Journal, 37(2), 76-78. doi: 10.1037/prj0000083

Erickson, M., Jaafari, N., \& Lysaker, P. (2011). Insight and negative symptoms as predictors of functioning in a work setting in patients with schizophrenia. Psychiatry Research, 189(2), 161-165. doi: 10.1016/j.psychres.2011.06.019

Giffort, D., Schmook, A., Woody, C., Vollendorf, A., \& Gervain, M. (1995). Recovery Assessment Scale. Chilcago, IL: Illinois Department of Mental Health.

Harris, M., Bebout, R. R., Freeman, D. W., Hobbs, M. D., Kline, J. D., Miller, S. L., et al. (1997). Work stories: Psychological responses to work in a population of dually diagnosed adults. Psychiatric Quarterly, 68(2), 131-153.

Heaton, R. K., Chelune, G. J., Talley, J. L., Kay, G. G., \& Curtiss, G. (1993). Wisconsin Card Sorting Test Manual. Revised and expanded. Lutz, Fl.: PAR. 
Holma, J., \& Aaltonen, J. (1997). The sense of agency and the search for a narrative in acute psychosis. Contemporary Family Therapy: An International Journal, 19(4), 463-477. doi: 10.1023/A:1026174819842

Kean, C. (2009). Silencing the self: Schizophrenia as a self-disturbance. Schizophrenia Bulletin, 35(6), 1034-1036.

Krawiecka, M., Goldberg, D., \& Vaughan, M. (1977). A standardized psychiatric assessment scale for rating chronic psychotic patients. Acta Psychiatrica Scandinavica, 55(4), 299308.

Latimer, E. A., Lecomte, T., Becker, D. R., Drake, R. E., Duclos, I., Piat, M., et al. (2006). Generalisability of the individual placement and support model of supported employment: Results of a Canadian randomised controlled trial. British Journal of Psychiatry, 189(1), 65-73. doi: 10.1192/bjp.bp.105.012641

Lecomte, T., Corbière, M., \& Laisne, F. (2006). Investigating self-esteem in individuals with schizophrenia: Relevance of the Self-Esteem Rating Scale-Short Form. Psychiatry Research, 143, 99-108.

Lecomte, T., Corbière, M., \& Lysaker, P. H. (2014). Une intervention cognitive comportementale de groupe pour les personnes suivies dans le cadre d'un programme de soutien en emploi (TCC-SE). L'Encéphale(0). doi: 10.1016/j.encep.2014.04.005

Lysaker, P. H., \& Buck, K. D. (2008). Is recovery from schizophrenia possible? An overview of concepts, evidence, and clinical implications. Primary Psychiatry, 15(6), 60-65.

Lysaker, P. H., Buck, K. D., Hammoud, K., Taylor, A., \& Roe, D. (2006). Associations of symptoms, psychosocial function and hope with qualities of self-experience in 
schizophrenia: Comparisons of objective and subjective indicators of health. Schizophrenia Research, 82, 241-249.

Lysaker, P. H., Clements, C. A., Plascak-Hallberg, C. D., Knipscheer, S. J., \& Wright, D. E. (2002). Insight and personal narratives of illness in schizophrenia. Psychiatry: Interpersonal and Biological Processes, 65(3), 197-206. doi:

10.1521/psyc.65.3.197.20174

Lysaker, P. H., \& France, C. M. (1999). Psychotherapy as an element in supported employment for persons with severe and persistent mental illness. Psychiatry: Interpersonal and Biological Processes, 62(3), 209-221.

Lysaker, P. H., France, C. M., Hunter, N. L., \& Davis, L. W. (2005). Personal narratives of illness in schizophrenia: Associations with neurocognition and symptoms. Psychiatry: Interpersonal and Biological Processes, 68(2), 140-151. doi:

$10.1521 /$ psyc. 2005.68 .2 .140

Lysaker, P. H., Lintner, J. I., Luedtke, B. L., \& Buck, K. D. (2009). Quantitative assessment of changes in self experience: An overview of research of the Scale to Assess Narrative Development. Israel Journal of Psychiatry \& Related Sciences, 46(2), 111-119.

Lysaker, P. H., \& Lysaker, J. T. (2008). Schizophrenia and alterations in self-experience: A comparison of 6 perspectives. Schizophrenia Bulletin, 36(2), 331-340. doi: $10.1093 / \mathrm{schbul} / \mathrm{sbn} 077$

Lysaker, P. H., Ringer, J., Maxwell, C., McGuire, A., \& Lecomte, T. (2010). Personal narratives and recovery from schizophrenia. Schizophrenia Research, 121(1-3), 271-276. doi: 10.1016/j.schres.2010.03.003 
Lysaker, P. H., Taylor, A., Miller, A., Beattie, N., Strasburger, A., \& Davis, L. W. (2006). The Scale to Assess Narrative Development: Association with other measures of self and readiness for recovery in schizophrenia spectrum disorders. Journal of Nervous and Mental Disease, 194(3), 223-225. doi: 10.1097/01.nmd.0000202512.54587.34

Lysaker, P. H., Wickett, A., \& Davis, L. W. (2005). Narrative qualities in schizophrenia: Associations with impairments in neurocognition and negative symptoms. Journal of Nervous and Mental Disease, 193(4), 244-249. doi:

10.1097/01.nmd.0000158376.53165.de

Lysaker, P. H., Wickett, A. M., Campbell, K., \& Buck, K. D. (2003). Movement towards coherence in the psychotherapy of schizophrenia: a method for assessing narrative transformation. Journal of Nervous and Mental Disease, 191(8), 538-541. doi: 10.1097/01.nmd.0000082182.77891.89

Lysaker, P. H., Wickett, A. M., Wilke, N., \& Lysaker, J. T. (2003). Narrative incoherence in schizophrenia: The absent agent-protagonist and the collapse of internal dialogue. American Journal of Psychotherapy, 57(2), 153-166.

Mueser, K. T., Salyers, M. P., \& Mueser, P. R. (2001). A prospective analysis of work in schizophrenia. Schizophrenia Bulletin, 27, 281-296.

Nieuwenstein, M. R., Aleman, A., \& de Haan, E. H. (2001). Relationship between symptom dimensions and neurocognitive functioning in schizophrenia: a meta-analysis of WCST and CPT studies. Wisconsin Card Sorting Test. Continuous Performance Test. Journal of Psychiatric Research, 35(2), 119-125.

Polkinghorne, D. E. (1996). Transformative narratives: From victimic to agentic life plots. The American Journal of Occupational Therapy, 50, 299-305. 
Provencher, H. L., Gregg, R., Mead, S., \& Mueser, K. T. (2002). The role of work in the recovery of persons with psychiatric disabilities. Psychiatric Rehabilitation Journal, 26(2), 132-144.

Rhodes, J., \& Smith, J. A. (2010). "The top of my head came off": A phenomenological interpretative analysis of the experience of depression. . Counselling Psychology Quarterly, 23(4), 399-409. doi: 10.1080/09515070.2010.530484

Rosenberg, M. (1965). Society and the adolescent self-image. Princeton: Princeton University Press.

Sass, L. A., \& Parnas, J. (2001). Phenomenology of self-disturbances in schizophrenia: Some research findings and directions. Philosophy, Psychiatry and Psychology, 8(4), 347-356.

Strickler, D. E. (2014). Rebirth through supported employment. Psychiatric Rehabilitation Journal, 37, 151-152. doi: 10.1037/prj0000068

Tabachnick, B. G., \& Fidell, L. S. (2013). Using Multivariate Statistics (6th ed.). Boston, MA: Pearson Education.

Van der Does, A., Linszen, D. H., Dingemans, P. M., Nugter, M., \& Scholte, W. F. (1993). A dimensional and categorical approach to the symptomatology of recent-onset schizophrenia. Journal of Nervous and Mental Disease, 181(12), 744-749. doi: 10.1097/00005053-199312000-00006

Ventura, J., Green, M., Shaner, A., \& Liberman, R. P. (1993). Training and quality assurance with the Brief Psychiatric Rating Scale. International Journal of Methods in Psychiatric Research, 3, 221-244. 
Ventura, J., Nuechterlein, K. H., Subotnik, K. L., \& Gilbert, E. (1995). Symptom dimensions in recent-onset schizophrenia: The 24-item expanded BPRS. Paper presented at the International Congress on Schizophrenia Research, Warm Springs, Virginia.

Wewiorski, N. J., \& Fabian, E. S. (2004). Association between demographic and diagnostic factors and employment outcomes for people with psychiatric disabilities: A synthesis of recent research. Mental Health Services Research, 6(1), 9-21.

Yanos, P. T., Lysaker, P. H., \& Roe, D. (2010). Internalized stigma as a barrier to improvement in vocational functioning among people with schizophrenia-spectrum disorders. Psychiatry Research, 178(1), 211-213.

Yanos, P. T., Roe, D., \& Lysaker, P. H. (2010). The impact of illness identity on recovery from severe mental illness. American Journal of Psychiatric Rehabilitation, 13(2), 73-93. doi: $10.1080 / 15487761003756860$

Zahavi, D. (2002). Schizophrenia and self-awareness. Philosophy, Psychiatry and Psychology, $8(4), 339-341$. 
Table 1

Participant Characteristics

\begin{tabular}{|c|c|c|}
\hline Characteristic & $M$ & $S D$ \\
\hline Age at participation, in years & 33.5 & 10.0 \\
\hline Number of hospitalizations in past year & 0.8 & 0.7 \\
\hline \multirow[t]{2}{*}{ Number of jobs held during lifetime } & 1.9 & 1.3 \\
\hline & $\mathrm{n}$ & $\%$ \\
\hline \multicolumn{3}{|l|}{ Gender } \\
\hline Males & 27 & 71.1 \\
\hline Females & 11 & 28.9 \\
\hline \multicolumn{3}{|l|}{ Race } \\
\hline Caucasian & 26 & 68.4 \\
\hline Other & 12 & 31.6 \\
\hline \multicolumn{3}{|l|}{ Citizenship } \\
\hline Canadian citizen & 33 & 86.8 \\
\hline Other & 5 & 13.2 \\
\hline \multicolumn{3}{|l|}{ Preferred language } \\
\hline French & 30 & 78.9 \\
\hline Other & 8 & 21.1 \\
\hline \multicolumn{3}{|l|}{ Marital status } \\
\hline Single, separated or divorced & 32 & 84.2 \\
\hline Married or domestic partner & 3 & 7.9 \\
\hline Not indicated & 2 & 5.3 \\
\hline \multicolumn{3}{|l|}{ Highest level of education } \\
\hline Less than high school & 11 & 28.9 \\
\hline High school graduate/GED & 8 & 21.1 \\
\hline College graduate & 7 & 18.4 \\
\hline University graduate & 6 & 15.8 \\
\hline
\end{tabular}


Graduate school

Not indicated

Duration without employment

Currently employed

6

15.8

1-12 months

15

39.5

13-60 months

6

15.8

More than 60 months

11

28.9

Psychiatric diagnosis $^{\mathrm{a}}$

Schizophrenia Spectrum Disorder

23

60.5

Mood Disorder

7

18.4

Dual Diagnosis (SMI + substance abuse)

12

31.6

Other

11

28.9

Note. GED = General Education Diploma; SMI = Severe Mental Illness.

${ }^{\mathrm{a} C}$ Combined frequencies exceed sample size due to comorbidity. 
Table 2

Baseline STAND Score Differences Between Individuals With and Without Employment at Follow-Up

\begin{tabular}{|c|c|c|c|c|c|c|c|c|}
\hline \multirow[b]{2}{*}{ STAND scale } & \multicolumn{2}{|c|}{$\begin{array}{l}\text { Employed } \\
(n=22)\end{array}$} & \multicolumn{2}{|c|}{$\begin{array}{c}\text { Unemployed } \\
(n=16)\end{array}$} & \multirow[b]{2}{*}{$t$} & \multirow[b]{2}{*}{$d f$} & \multirow[b]{2}{*}{$p$} & \multirow[b]{2}{*}{$\eta^{2}$} \\
\hline & $M$ & $S D$ & $M$ & $S D$ & & & & \\
\hline Illness Conception & 3.90 & 1.11 & 4.41 & 0.79 & -1.52 & 36 & .136 & .06 \\
\hline Alienation & 3.34 & 1.42 & 4.53 & 0.70 & -3.40 & 32 & $.002 * *$ & .24 \\
\hline Agency & 4.02 & 1.05 & 4.23 & 0.82 & -0.67 & 36 & .509 & .01 \\
\hline Social Worth & 2.74 & 1.05 & 3.52 & 0.69 & -2.58 & 36 & $.014 *$ & .16 \\
\hline Total & 14.01 & 4.02 & 16.71 & 1.99 & -2.73 & 32 & $.010 *$ & .17 \\
\hline
\end{tabular}


Table 3

Means, Standard Deviations, and Intercorrelations for Work Intensity at Follow-Up and Predictor Variables at Baseline

\begin{tabular}{|c|c|c|c|c|c|c|c|c|c|c|c|}
\hline Variable & $M$ & $S D$ & 1 & 2 & 3 & 4 & 5 & 6 & 7 & 8 & 9 \\
\hline Work Intensity & 15.44 & 15.25 & -.01 & -.07 & -.28 & $.35^{*}$ & $-.36^{*}$ & $-.60 * * *$ & -.28 & $-.51 * *$ & $-.53 * *$ \\
\hline \multicolumn{12}{|l|}{ Predictor Variable } \\
\hline 1. WCST - CC & 4.63 & 1.94 & - & $-.87 * * *$ & -.04 & -.24 & $.40 * *$ & .18 & .20 & .21 & $.29 *$ \\
\hline 2. WCST - PE & 18.09 & 15.00 & & - & .24 & .10 & -.23 & -.03 & -.07 & -.06 & -.12 \\
\hline 3. RSEWS & 32.63 & 4.64 & & & - & -.26 & .04 & $.31 *$ & .27 & $.35^{*}$ & $.29 *$ \\
\hline 4. BPRS - Neg. & 1.70 & 0.67 & & & & - & $-.52 * *$ & -.24 & $-.38 * *$ & $-.39 * *$ & $-.44 * *$ \\
\hline 5. STAND - IC & 4.06 & 1.03 & & & & & - & $.57 * * *$ & $.63 * * *$ & $.50 * *$ & $.80 * * *$ \\
\hline 6. STAND - AL & 3.79 & 1.35 & & & & & & - & $.65 * * *$ & $.75 * * *$ & $.91 * * *$ \\
\hline 7. STAND - AG & 4.06 & 0.98 & & & & & & & - & $.47 * *$ & $.81 * * *$ \\
\hline 8. STAND - SW & 3.08 & 0.99 & & & & & & & & - & $.81 * * *$ \\
\hline 9. STAND - Total & 15.01 & 3.66 & & & & & & & & & - \\
\hline
\end{tabular}

Self-Esteem as a Worker Scale; BPRS - Neg. = Brief Psychiatric Rating Scale - Negative Symptoms Scale; STAND = Scale to

Assess Narrative Development; IC = Illness Conception; AL = Lack of Alienation; AG = Agency; SW = Social Worth.

$* p<.05 . * * p<.01 . * * * p<.001$. 


\section{Annexe A}

\section{Consignes et texte pour l'entrevue Indiana Psychiatric Illness Interview}

Source: Lysaker, P., \& Buck, K. D. The Scale To Assess Narrative Development: A brief overview. Manuscrit non publié.

This Interview should encourage participants to tell their story as they will with the interviewer asking only the questions listed below. Comments may be necessary to cue the person that the interviewer is listening. These should be as reflective as possible, not introducing content the participant has not mentioned. Do not ask the individual to fill in chronological gaps or probe about information that he/she did not mention in his/her initial telling of the story.

Questions as listed below do not have to be asked in order and the interviewer should accommodate the client's narrative. The overarching value should be to provide a setting in which the client's narrative as it currently exists is able to emerge. The interview may be introduced as simply as: "The purpose of this interview is for me to understand as carefully as possible your story of yourself including what has gone wrong, what has not gone wrong."

\section{Section I: General Free Narrative}

- I'd like you to tell me the story of your life, in as much detail as you can, from as early as you can remember up to now. If it helps you to organize your story, you can divide it into chapters or sections. Any questions?

\section{Section II: Illness Narrative}

- Do you think you have a mental illness (MI) and if so what do you think it is?

- Did you have MI in the past?

- What caused these problems?

- How do you feel about having this MI? 
- What is going to happen to your MI in the future?

\section{Section III: What's Wrong vs. What's Not Wrong}

- Since your MI what about you has changed and what has stayed the same?

- Vocational function (work/school)

- Social function (family/romantic, friends/acquaintances):

- Others' lives (How have others' lives changed/stayed the same since your MI?)

- Cognition/emotion

- Personality (who you are)

\section{Section IV: Degree of Influence of Illness Construct}

- To what extent and in what ways does your MI control your life?

- To what extent and how well are you able to control your MI?

- How have others been affected by your mental illness?

- How have others affected your mental illness?

Section V: The future, hopefulness and satisfaction

- What do you see ahead of yourself in the future? 


\section{Annexe B}

Grille de cotation pour la mesure Scale to Assess Narrative Development

Source: Lysaker, P., \& Buck, K. D. The Scale To Assess Narrative Development: A brief overview. Manuscrit non publié.

\section{Illness Conception (IC)}

1. The client does not perceive anything is wrong on any psychological level

2. The client perceives pain or confusion but only in a global or vague manner (e.g., "My mind is confusion, my self is unintelligible")

3. The client perceives only a limited number of specific psychiatric problems or challenges with minimal and perhaps implausible or limited elucidation (e.g., "I am depressed and see visions")

4. The client perceives many discrete problems but without a plausible account of etiology (e.g., "I am depressed, withdrawn, have hallucinations caused by the devil")

5. The client perceives that there are many discrete problems or challenges with elucidation and a plausible account of etiology (e.g., "I am emotionally withdrawn, have hallucinations of devils and angels and that is because of losses in my life and a chemical imbalance")

\section{Lack of Alienation (AL)}

1. No evidence that the client perceives any closeness to others nor desires such closeness

2. The client expresses a desire for closeness but has only the thinnest connection with others tempered by fear (e.g., "I thought about calling my father but couldn't because I was afraid")

3. The client has a few social connections that exist because of family ties/passivity, or fulfillment of role (e.g., "I talked to my father briefly when he called last week") 
4. The client has multiple ties and plays an active role but there is no evidence that these are more than casual (e.g., "I visited with my father on Thanksgiving Day but didn't say very many things that were all that personal")

5. The client perceives that at least one fulfilling intimate tie with a discernible person (e.g., "I walked with my father and we talked about many of our worries")

\section{Agency (AG)}

1. No evidence the client perceives they can affect events in their own life and nor can discern causes of life events

2. The client perceives that discernible forces affect life but those forces are exclusively or almost exclusively, supernatural or implausible (e.g., "The government is controlling the traffic outside my house")

3. The client perceives that events in their life are influenced only by forces outside of them, but those forces are plausible, can be discerned and influenced. (e.g., "I did it because my brother said so")

4. The client perceives that they can affect their own life minimally or can affect their lives but primarily by resisting or passive protesting (e.g., "I resisted the temptation through sheer will power")

5. The client perceives that they can act and affect life course actively (e.g., "I decided to talk with my mother and it helped everything")

\section{Social Worth (SW)}

1. No evidence that the client perceives that they have value to others, actual or potential 
2. The client perceives they may have minimal value socially but mainly because of past deeds. There is little evidence of future hope. The client may note that they have skills not actualized in role performance (e.g., "I was a good cook but don't cook anymore”)

3. The client fails to perceive current value to others, but may have value because of past deeds and has potential to be of value in the future (e.g., "I put in an application for a job")

4. The client perceives that they are of currently of some value to others in general, but not to specific persons or in a way that uniquely distinguishes them (e.g., "I do my job well")

5. The client perceives that they are of value to others presently, with reference to specific contributions or benefits observed by others (e.g., "My daughter relies on me for emotional and financial support") 